\title{
Home and care in a Changing Society
}

\author{
Mohamed Gamal Abdelmonem and Antonio Argandoña
}

\begin{abstract}
The changing demographics of our modern society have inevitably impacted the dynamics and intimate relationships within the home from being personal and private within emotional domain of the family to that of work relationship, either with regard to domestic work, care for older people, work from home, or supporting people with special needs. Modern society has posed new challenges to the traditional work and care relationships in the domestic sphere that required in depth scrutiny of the changing dynamics in the increasingly complex and multi-dimensional domain of the home. Looking at dichotomies of private-versus public, place of care versus place of work, and how it caters for special needs of different people, this chapter introduces an interesting multi-disciplinary approach to investigate the home from multiple angles as covered in the book by scholars, academic, professionals, and practitioners. These papers have been complemented by feature essays authored by politicians and policymakers with specific case in point. Centred around three streamlined themes, this chapter makes the case to cover the relationship and dynamics of Care, People, Work in the home.
\end{abstract}

\section{Introduction}

Modern society has elevated the family and household matters from their formerly private position to that of concerns of the political institutions. The emergence of society, seen by Hanna Arendt in the rise of housekeeping, its activities, problems and organisational devices, has moved the home from the shadowy interior of the household into the light of the public sphere. It has not only blurred the old borderlines between private and political, but has also changed almost beyond recognition the meaning of the two terms and their significance for the life of the individual and the citizen (Arendt, 1958:28). Housing policies, management of households and professional rules of home workers are a few discrete examples of how the institution of the society interferes in the matters and system of the home.

A quick look at the housing layout of most European cities shows clear signs of accelerating displacement of the family from their urban centres towards the peripheries. There is increasing segregation and distance between places of work and living spaces, lengthier daily journeys between work and home. In the search for good careers, young people live in shared accommodation near their workplaces in the centre. People with families have to live at greater distances from work and provide alternative means of caring for their house, children and elderly. Such spatial segregation between where people work and live has resulted in a decline of support from within the family and has increased the demand on outside care services, be it domestic workers, childminders, or care for elderly people. Hence, other forms of professional relationships were brought into the home at a time when homeowners are experiencing a greater distance between work and home.

However, we need to be clear about what we mean by home. Home is an everyday notion that carries subjective clarity as well as collective ambiguity. Are we talking about the home of the family, the home of the collective group of individuals? We are living in an ever more dynamic and mobile environment where our activities overlap and the traditional boundaries of privacy have become blurred regarding where a certain activity stops and another starts. In our contemporary society, we have a multiplicity of homes, of which some are not such private domains as they used to be. Homes 
could host professional and work activities or provide medical care. Hence, we can here introduce a common understanding of what do we mean by home and our understanding of its complex and multi-layered nature.

Home is that contested environment where several processes, interactions and engagement are at work on constant basis. Over time, the challenges to home as an institution, emerged from changing socio-economic and cultural landscapes that offer new problems and opportunities based on the various elements that make up the home (family, marriage, motherhood, fatherhood, children, home production and consumption, housing, work, health, upbringing and education, family policies, etc.). These challengers are tackled in this book from diverse viewpoints of science and humanities research fields. Most of current endeavour, however, are quite specialised, although there are also a limited number of studies that deal with such topics in a more interdisciplinary way.

While books on home relations and environments are mostly defined by specific discipline or research area, such as social psychology, environmental psychology, sociology, humanistic geography, ethnology, sociology, this book offers a unique interdisciplinary approach that engage multitude of research domains based on shared enquiries on home as place of care, of people and of work. This book aims to develop an enquiry on the function and practices of the contemporary home. It adopts the broader conception of the home: including people (the family), place (the housing), environment (neighborhood, city, town), society, taking it as the unit of analysis and consider its multifaceted dimensions: anthropological, ethical, economic, political, social, psychological and spatial. It looks to: a) identify and sensitize different experiences, situations, challenges of the home; b) offer a series of diagnostic investigations that cover a number of issues from the perspectives of health, care, work and engagement; $c$ ) instigate a number of creative perspectives towards new evolutions of the way home works and operates for modern families and stakeholders; d) evaluate the results: impact on the home and on the people, on the nearby community, on society; e) analyse and contribute to the design and execution of public policies on home and care; $f$ ) interrogate different impacts on people (knowledge, skills, values, virtues ...) and environments (family, business, social entities, public bodies ...)

This volume is a collaborative and multidisciplinary endeavor with contributions from the point of view of different disciplines and from practice. There are descriptive, theoretical, empirical and practical chapters. The thread of the book is the triangle of people + work + care. Many people participate in the home, with different degrees of involvement: not only the family members, but also the extended family, those who help from outside, those around, the most distant, the institutional collaborators (schools, universities, medical centers, homes for the elderly and disabled, etc.)

We look at the home as a multipurpose organization whose tasks include reproduction, nutrition, learning and socialization of children, production of goods and services, care for the sick and elderly, provision of physical, psychological and ontological security, a means for the acquisition of a social identity. It is a place where virtues are learned, a door to enter society, a place from which one leaves every day, but to which one returns, and to which we all hope to return in the final stages of our life. This multipurpose organisation implies that people must perform a set of functions, much more extensive and varied over time than those of other organizations, however complex they may be, such as a hospital. Everyone at home has to be willing to perform very different tasks. 
A home encompasses people, community, and space or environment in a society, in which the home performs a function

${ }^{1}$. The number of people is not the most important factor: the home can be single-person, or it can take on more complex forms, such as the nuclear family, the extended family, the single-parent family, separated parents, compound family, same-sex parents, or people who live in a home for the elderly or the disabled. However, its relational nature is important, because it determines its social function within its immediate (village, neighbourhood, city) and general environment (society at large). This book is about the home, its nature and its functions, its importance, difficulties and hopes. It is the fruit of the work of 27 authors from different disciplines and countries, with different approaches, some of them theoretical, others empirical and yet others whose outlook is eminently practical. We have grouped them in three parts, focused on care, people and work, because these are three basic aspects of the home that account for its social function. In the following pages, we will explain very briefly the book's underlying conception of the home: first, its social function; next, the three themes around which the three parts of the book revolve: care, people and work, led by three key feature articles that drives the agenda for our discussions.

This book offers a rare insight into the multiplicity of challenges from theoretical, practical, policy perspectives of the home in the Twenty First century, and how professionals and researchers alike tried to address them. Above all, it highlights the commonality of these challenges and how do the ordinary people relate them to their own daily lives. But, before we delve into the detailed arguments introduced in the book chapters, we introduce her a basic and shared theoretical framework of the home and its meanings as shared throughout this book.

\section{Making Sense of the Home}

We have inherited this subtle notion of the home as a haven and refuge that transcends different conditions and relations of living within the house. Homes are socially constructed that have continually changed their forms, uses and meanings ${ }^{2}$. While houses are built with the capacity to serve a wide range of social activities that differ through generations and vary according to material means, homes are constructed out of continuities of social traffic, activity, and conduct (Abdelmonem 2016). Hence, we seem to have a conceptual contradiction in the attributes of the home. How it could be private, while it associates its form, organisation and largely meaning with the commonality of a group, culture or society (Abdelmonem, 2011). As a social-spatial system of living, the home was integral to circles of selective socialising that overlapped public and private life with obligation and trust beyond the family to the expansive formation of the city and society at large. In the second half of the Twentieth Century, we have sought better understanding of the home as a multidimensional concept ${ }^{3}$, hence, multidisciplinary understanding of its formation and evolution as human practice is needed (ibid). Since the mid-1980s, the home has been subject to a well-documented and longestablished history of architecture and the built environment from various points of view and research areas: sociologists, environmental psychologists, architects, and historians. From Nietzsche to Martin Heidegger and Hannah Arendt, the act of building and inhabiting space is a process of mediation with nature and contextual condition.

Home emerges as a stronghold territory, in which certain security measures, control and defence are continuously at work. Home is an intermediate territory that lies between the personal spaces, in which people maintain certain distance from others, and between public spaces, in which individual requirements are superseded by the superior shared interest of society. Homes fit the definition of human territoriality as 'the relationship between an individual/group of people and particular physical settings that is characterized by a feeling of possessiveness, attempts to control the appearance and the use of space' (Bower 1980: 179). Homes, thus, could be realized through a network of spaces (indoor and outdoor) that a person uses routinely as a haven with high degree of comfort and intimacy. They envisage specific codes of human behaviour learned through cultural training and that require 
adjustment every time people cross their boundaries. Spatial configurations of homes are not limited to the physical boundaries; rather, people construct their home domain beyond what appear to be physical boundaries. The immediate front of a house is part of home territory. With the emergence of new technology and telecare, on the other hand, some of the most private spaces in the home become accessible to medical and social care professionals, as experienced by many elderly people. Home has become again a place of work, with many self-employed and young professionals working from home. Such changing dynamics at home require continual investigations to what a home means in certain time and to certain generation.

\section{The Home}

Home is an ambiguous term that retains different meaning within different contexts and disciplinary approaches. Its inclusive meaning reflects the physical parameters of a residential space (house, dwelling), place (neighbourhood, town); environment (domestic life), as well as the social determination of a particular community. Home is defined by Oxford English Dictionary as:

'A dwelling-place, house, abode; the fixed residence of a family or household; the seat of domestic life and interests; the dwelling in which one habitually lives, or which one regards as one's proper abode. Sometimes including the members of a family collectively; the home-circle or household. ${ }^{4}$

Such inclusive definition that encompasses a number of meanings shares similar references but different meanings about domestic environments, for individual members of the household or for the social makeup of the family. However, the contemporary literature of domestic architecture alienates itself by use of three basic terminologies: home, house and household. This emphasis shows that home is used for the analysis of the environment, house for the characteristics of physical space and its economic aspects of production. The household refers to the economic unit that occupies the house, its affordability and ecology 5 . Home, as we acknowledge it in this book, refers not only to the spatial settings that accommodate the personal and family socio-cultural, psychological needs and enables certain sets of functions, like social space, a place for work and care, but we refer to the home as the environment and social conditions that enable and facilitate these functions. Its boundaries are constructed based on conditions of functions, relationships and economies of contemporary society.

Different analytical approaches tend to deal with the house as a unit of accommodation with a number of objective physical attributes, such as size, amenities, and form. Some reduce the house to its materialistic nature, that is, 'the bricks and mortar or other building materials that comprise the constructions within which people live' (Kemeny 1992). The house is used as a unit of planning and target of the governmental policies (Housing policies). As a physical product, it is determined; it could be counted, improved and measured in terms of housing stock and future requirements according to population growth. In this sense, Housing is becoming a consumable product, bought, used and disposed of based on the changing needs and conditions of its occupants (Abdelmonem 2016). According to the well-known view of Le Corbusier, the house/dwelling is 'a machine for living' (Harries 1975). At the basic level, homes provide the space which defines many activities that constitute primary relationships in the home and for those living within it, those who care, work and support each other.

\section{The social function of the home}

An institution's social function is what justifies its existence and its role in society and confers its legitimacy in the public sphere. This legitimacy is determined in turn by recognition, not in a law (legality), nor even by public opinion, which can be volatile, but by individual citizens. "Human 
development and the advancement of society will only be possible if it is based on societies made up of stable families organized in a personalized home environment; this is what will lead to a stable and personalizing society" (d'Entremont, 2018, 164). Here, we can identify three levels in the explanation of this social function: 'why' the home exists as an institution, 'for what' it exists, and what is its 'purpose'.

The 'why' looks toward the past and seeks to give an explanation. We need food, physical protection, shelter when we are tired or sick, something that allows us to remember who we are ... These needs can be met in many ways, with better or worse results but, as a general rule, they are met best when we have a home ${ }^{6}$. The 'what for' looks toward the future. In the home, someone (family members or external collaborators) prepares our food, protects us, offers us an identity ... this may be one person, or several people, or everyone, with cooperation from people outside of the home and material resources: the house, the furniture, the household appliances, and everything that makes 'our' home special. The 'what for' invokes a function, first for its members, but later on for others outside of the home, and eventually reaching society as a whole (Argandoña 2018).

A home without a 'what for' can function for quite some time; it simply has to satisfy the motivations of the people who are its members -the 'why': in other words, perform the functions of a restaurant, hotel, social club, cinema, sometimes hospital. But it will be lacking a 'purpose', which is the 'what for' as defined, shared and accepted by that particular community's members. This 'purpose' is usually not stated explicitly (families usually do not write a mission statement, agreed and implemented by all, as is the practice of many firms), but this does not mean that they do not have an implicit 'purpose' or 'project'. The lack of a 'project', or the existence of several unshared 'projects' implies a lack of unity, and this is a threat for the home's continued existence.

The key is the development of knowledge, skills, attitudes, values and virtues. The works done in the home, mentioned before, are directed, directly or indirectly, to that learning and formation, including the task of "replicating" the organization in future new homes, which will be very different, but which will be rooted in the existing homes now. The home has many dimensions: temporal, spatial, economic, ethical, legal, cultural, communicative, political, psychological, sociological, religious, and others (Argandoña 2018). Here, we refer to three aspects of the home's 'purpose' which provide the rationale for how this book is organized: care, people and work. Each of these sections are fronted by a key feature article that drives the research agenda in its field, led by Lord Richard Best, Professor Sheila the Baroness Hollins, and Professor José Víctor Orón Semper. That is why the three dimensions, people, work and care, that are developed in the book are important:

PART ONE: ON CARE. Because what people do at home is to take care (of the people, of the home, of the future, of society). The different chapters of the first part develop various aspects of care: with everyone, with the vulnerable (children, the elderly, the sick), in preparing for aging in all aspects, such as food, health, sustainable housing.

PART TWO: ON PEOPLE. The home is for people, and they contribute in many ways (also those who apparently cannot contribute, as babies), with special consideration of children, elderly, disabled and also caregivers.

PART THREE: ON WORK. Work, in a very broad sense, from the material tasks of the home, performed by family members or external collaborators, to tasks that we do not usually call work, such as resting together, chatting, listening to others, etc. Including social perceptions of work at home in different environments, and some special types of work, such as on demand economy and working from home.

Below we discuss the makeup of those parts and their theoretical underpinnings from different inter-disciplinary and multi-disciplinary perspectives.

\section{On Care}


There is growing understanding of the challenges facing health services and providers to offer care at formal healthcare institutions. With public spending on health and social care is in growing decline, the culture of care is shifting towards providing care at home, and wherever possible by the family with local community support. Hence, the relationship between the home and care is getting very crucial in the make-up of twenty first century homes. The home exists because it satisfies needs. The first need that appears in people's lives is linked to their vulnerability: we are born biologically destitute, unprotected, unable to survive without other people's help; that is why we need an institution ${ }^{7}$ that gives shelter, food, protection, that teaches us and helps us learn (sometimes, the lessons can be very hard) how to be human beings ... (Marcos 2016, Marcos and Bertolaso 2018). And here is where care appears as one of the home's basic components. Care requires a safe, pleasant physical environment, which is the home's spatial dimension; a community of people who perform these functions, which is the family, in its different forms, and an extensive range of goods and services provided by the neighbourhood, the village, the city ... and, ultimately, by society in general: all of the elements of the home are embraced in the concept of care ${ }^{8}$.

While the specific needs related with care change over time, the need for care persists: we are vulnerable and dependent, even when we are at the peak of our strength and physical and mental capacities. The home is a place where we can take shelter from inclement weather, an opportunity to enter and retire into our private space, a place for mental repose, a means for recouping strength ... This is obvious at times of illness or disability, or in the infirmity of old age ... but the home is always a place -albeit not the only one- where everyone can find care.

And it is also a place where we learn to care for others, whether driven by biological forces or sentiment, whether for self-interest, selfishness or love. Caring is giving of oneself, and this is learned in the home: not just in the home, but it is the first place where this learning takes place. The first thing that a baby sees when it opens its eyes is usually the face of its mother or father while they are caring for it. It is true that the home is intended, first and foremost, to foster individual autonomy, particularly of children and young people. However, autonomy is the counterpart of dependency: the autonomous person chooses how he or she will put him or herself at the service of those who are vulnerable and dependent-and that is care (cfr. Marcos and Bertolaso, 2018).

The literature on the ethics of care has grown considerably, particularly since the works of Carol Gilligan (1982) and Nel Noddings (1984). Although opinion is not unanimous regarding the foundations of this ethics, there are certain qualities which seem to be particularly useful in an appraisal of care in the home ${ }^{9}$. A number of definitions of care can be found in the literature on ethics: as a counterpoint to the concept of justice, as a type of work, as a special relationship, as a practice, a value, a disposition or a virtue ${ }^{10}$. Whatever the definition used, care is a unique relationship that involves two parties, the 'one caring' and the 'cared-for', both with obligations (Noddings 1984). ${ }^{11}$ In the home, this relationship is always personal and direct (Bubeck 1995; cfr. Zárate et al.-, chapter 2), but it can never be considered a commercial exchange (Bahr and Bahr, 2001), ${ }^{12}$ nor even as fulfilment of a contract (Held, 1993), and much less as driven solely by selfish motives. ${ }^{13}$ Neither can care relationships in the home be reduced to the mere performance of deontological duties. On the contrary, they will include other qualities such as gentleness, agreeability, compassion, sympathy and good temperedness (Baier 1987), which align with virtue ethics (Halwani 2003, McLaren 2001, Ruddick 1989).

Tronto $(1994,126-136)$ argues that care is a practice, which has four stages or virtuous dispositions: a) attentiveness, the predisposition to understand that a particular person has a need; b) responsibility, the attitude of responding and taking responsibility for the provision of care; c) competence, the skill in offering effective care; and d) responsiveness by the person receiving the care, which does not mean reciprocity, as this is not always possible in situations of vulnerability and inequality, but the effort to understand what those who are in this vulnerable position have expressed.

These reflections on the nature of care, although they are usually directed toward other activities, such as medicine, nursing or education, are particularly important for the home. When Hamington 
$(2004,3)$ says that "care is committed to flourishing and growth of individuals", he seems to be thinking of the home's social function, particularly with respect to children ${ }^{14}$. But, in fact, it applies to everyone, so he adds that care "acknowledges our interconnectedness and interdependence" (Ibid., 3; Mayeroff 1971). Since its inception, the ethics of care has been associated with female ethics, because its roots were found in motherhood. However, care is not something that is exclusively female. The experience of many homes shows that care relationships exist between parents and children (although, logically, with distinctive features in each case), and also between siblings, between other relatives and with people who, while not members of the family community, contribute to the performance of the home's tasks.

Care has a dimension that goes far beyond the boundaries of the home. "The home is a place where one 'learns to live' during a long and changeable process. It is here that children receive knowledge and develop abilities; they internalize rights, autonomy, participation, mutual respect and freedom. It is a place where the other is acknowledged, where one participates and also learns how to manage disputes and diversity... and this is learnt precisely in coexistence with the rest of the family members, and is therefore joint and shared learning" (Argandoña, chapter 10). It is logical that the home should be the place where one learns to care for others, projecting this responsibility toward other spheres outside of the home: for example, care for the environment (Brizi, chapter 5).

To frame this section, a feature articles is written by Lord Richard Best. Under the title of 'A Home for Later Life', Lord Best urges us to critique our decisions today with a view of the impact on our later life. He discusses the inability of the market to provide the homes needed for an ageing society and proposes key steps to achieving the homes we will need. The argument of the multidisciplinary approaches to care, is developed over four chapters. In Chapter Two, Belén Zárate, Remei Agulles and Consuelo León discuss the transformation of other care environments in Homes, looking at the characteristics of care within the family and how both health care and residential care in Spain have developed new means of collaborative patient-centred approach. Costa and Esteve in Chapter Three, on the other hand, investigate the healthy home at early years looking at guidelines to build healthy home interior environments with particular attention to children development at early stage. It makes the case for building a healthy home with solid structures and materials to make healthy indoor environments. In Chapter Four, Greaves-Fernández and Rabiela-Sotelo discuss the high-risk practices occur in the homes of families suffering from food poverty. They look at how care could be affected by everyday practices and the implications on healthy living at home and how education is central to building awareness for such growing segment of society in an attempt to safeguard both the health and the wellbeing in the homes. Responsible citizenship and our common home is the key focus of Maria Rosaria Brizi, Chapter Five, where she addresses sense of responsibility and commitment towards the natural environments from within the household. She explores embracing the principle of sustainability in everyday living and making homes sustainable practices.

\section{On People}

The person is the core of the home because he has dignity, "the inalienable value of worth every human being has for the fact of being human" (Zárate et al., chapter 2). The home is a means, not an end; it exists for people. The restaurant, the hotel, the social club, the cinema and the hospital that are part of the home, as we said earlier, are also focused on the person, but the home has a 'purpose' which is not the sum of different services, no matter how important they may be, but the development and flourishing of the person, of all persons, from the moment of their birth and during the rest of their lives. ${ }^{15}$

"The person's place in the home can be analyzed primarily from two viewpoints: privacy and relationality. The home is the place for the person's privacy, to which one retires to keep one's life in order and regain control over it: it is 'the place to which one always returns' (Alvira, 2010), 'that most recondite, private, secure and comfortable place for the self, where it takes shelter from the natural 
world, to where it belongs as its innermost shelter, and where it addresses the world and the other, opening itself to transcendence' (Patrão Neves, 2018, 73). In the home, we can be as we are, because we are accepted for what we are, not for what we have, give or do. (...) 'it is in the home where we find the true expression of the interiority of the human being, a natural base that is necessary in order to carry out the tasks demanded by society' (d'Entremont, 2018, 170)" (Argandoña 2018, 13). In short, the home is the "space open for the quiet flourishing of what is human" (Marcos and Bertolaso, 2018, 35). This is probably what best defines each home's project, and its function in society.

The other way of understanding people in the home is their relationality: not because the person is his relationships, but because he understands himself in his relationships, and because "home is that site where relation originally occurs and within which individuals are constituted" (Patrão Neves, 2018, 73). These relationships determine people's expectations in the home, what they give and receive (and what they themselves receive when they give), at the physical, mental, emotional, cognitive or ethical level. "This entails rights and responsibilities, work, formal organization (rules, judgment, hierarchy, authority) and informal organization (trust, implicit understanding, putting aside personal criteria to favour the needs of other members), material possessions, human and social capital and many other elements, all of them focused on achieving certain material and spiritual results for the people and the internal community" (Argandoña, 2018, 14; Allan and Crow, 1989).

However, people's relationships are not limited to the narrow confines of the home, but are open to the outside world: the home is "within but open" (Marcos and Bertolaso 2018, 53). Society in general, and individual social communities (neighbourhood, village, city, companies, educational institutions, social organizations, and many more) receive the 'gift' of strong homes, that efficiently fulfil their purpose, namely, the human and social development of its members. In turn, the home is supported on the legal, cultural, social and economic framework of society and its individual communities, its policies and services. Ideally, these are win-win relationships, although they can also be destructive ${ }^{16}$.

To look at human's centered approach, the Second Section of this book, People, encompasses a number of studies that look at the experience of people with special needs, like ageing parents, children with disabilities, care giving challenges, as well as how the home environment impacts of our cognitive and sensation development. The section opens the argument with a feature article by prominent scholar and campaigner, Professor Sheila The Baroness Hollins, Under the title, 'My Home, my life: Aspirations of people with intellectual disability for an ordinary home and an ordinary life'. In this article, Baroness Hollins looks at the barriers and challenges to living an ordinary life at home as opposed to living in institutional care, where individuals with intellectual disabilities can find themselves in a locked ward. The section follows with four chapters that tackle theoretical and empirical investigations. In Chapter Six, Usochi llozumba, investigates the anthropological construct of the home and its impact on the our cognitive, sensation and intellectual knowledge in light of Sarti's scientific-experimental thesis of response-transmission interaction, Piaget's cognitive development stages, and Sanguineti's metaphysical approach to the study of human cognition.

The complexity and challenges of ageing parents living with adult's person with disability was the focus of Horacio Joffre's paper, Chapter Seven. He discusses chronic sustained and systematic stress that face ageing parents looking after a disabled person and the need for public policies, education, recreation, health services that support such complex needs and environments. Along similar line, Aleksandra Kroll looks, in Chapter Eight, at special care needed for disabled children at home, especially when family members become caregivers to both mentally and physically disabled children at home. In Chapter Nine, Gabriella Facchinetti et al, focus on the expectations of elderly people experience and needs for their residential care facilities. it explores what contributes to the feeling of the "sense of home" and what are the housing needs of elderly through a qualitative study of fourteen older adults in Rome. 


\section{On Work}

The people who make up the home, and those who collaborate with them, whether regularly or occasionally, are continuously performing actions ${ }^{17}$. We could call some of these actions work, because of their productive or operational qualities, or because they entail effort or fulfil a duty or obligation, with or without an explicit remuneration. However, in the home, the concept of work becomes broader and goes beyond being a task-performing activity (Witzel and Warner 2015). There may be one or more motives in any human action: extrinsic (because of the consequences received from the environment or other people: goods and services, approval or reprobation, etc.), intrinsic (the consequences that the action has directly on the agent: satisfaction, learning), and transcendent or prosocial (the consequences on other people which, in turn, generate consequences -moral learning- in the agent) (Pérez López 1993, Argandoña 2008).

These actions can be individual or shared; in the case of the latter, there is cooperation between several people, each one with their own motives, but who are all interested in a shared result or purpose (the 'what for'). For example, if they are working together on preparing a meal, everyone wishes to satisfy their hunger (extrinsic motivation), they are doing something that gives them pleasure (intrinsic), and they also want the other participants to satisfy their hunger and have a good time (transcendent). However, everyone has a shared purpose in this joint action, which may simply be to prepare a lunch together, in a coordinated manner, or perhaps something more ambitious, such as a party, or a celebration for one of the people there.

The important thing in this action, which has some of the qualities of work (effort, dedication, order, discipline), is the shared purpose, which does not necessarily need to align with the agents' motives, and which can be something as simple, but as important, as wanting to do something together. Sometimes, one person's action is independent from another person's action; other times, there are strategic interdependencies, so that the results of one person's action depend on the results of another person's action; in these cases, social motivation is needed, which will be part of each individual's intrinsic and transcendent motives. These actions require coordination and commitment, generating a learning that strengthens the home's purpose. And they are often part of the care we talked about earlier.

On this basis, we can now identify what characterizes work in the home: awareness of human vulnerability and dependence and, consequently, responsibility for the service. The social value of the work done in the home is not confined to the economic value of certain goods and services that are produced; it also contributes to the welfare of society and people's development (Mclntyre 1999; cfr. Frezza et al. 2017).

When one talks of work in the home, this can encompass a variety of situations. We usually highlight the work done by the mother, and rightly so, because historically it has been the mother who has performed most of these tasks. However, increasingly we must take into account the work done by the father which, while having different qualities from the work done by the mother, is no less important. And the work done by the children; often the first school for work, the work done in the home leaves a lifelong mark, and includes when they give back to their parents the services they received when they were children. And, lastly, the work of external agents, from shopping, cooking, cleaning and tidying up to looking after children, disabled people and the elderly: such carers often adopt as their own the home of the people they care for, because this care is more than just time spent on a particular activity. Work is always care.

Part Three on Work, starts with feature article, addressing educational approach for children growth at home. The article written by José Víctor Orón, focuses on how the UpToYou educational program focus on how emotional education of young children should be understood in the family environment during the first years of life, from the theory of attachment and social reference, the emotional development and complexity perspectives. This part is made up of additional four chapters that looks at the economics of working at home from theoretical and practical point of view. In Chapter Ten, 
Antonio Argandoña investigate the theoretical approach to work at home as a shared human action that takes place in a special community. He looks at personal and collective motives, common purposes, coordination and the trust the collective work generates. Teresita Abay Krueger discusses the Alignment of On-Demand Economy with the Home as a Workplace, as the future work agendas focus on the home, in Chapter Eleven. In Chapter Twelve, Sandra Idrovo Carlier et al., discuss a Crosscountry comparison for Caregiving in the home in Latin America. They look at how housework is perceived and how it helps develop skills in ten Latin American countries and Spain. They report results show certain general homogeneity in their perception but with some statistically significant differences among some of them and when considering gender. In Chapter Thirteen, Kathleen Farrell studies the impact of the evolution of technology as key to teleworking from home and its impact on domestic life. She looks at how such changing dynamics at home whilst provides women more opportunities for flexible working conditions, it has an impact on work/life balance and deprive the family for its physical independence from work. A managed balance through set barriers of time and space. Finally, Audrey Tan introduces a novel structured programme on developing life skills from Kenvale College, Sydney, to address the true value of the work in the home in Singapore. Through the programme, participants are challenged to develop professionalism in the work they do at home as a fundamental role in developing character strengths and value systems in children

\section{References}

Abdelmonem, M.G., 2016, The Architecture of Home in Cairo: Socio-spatial practice of the Hawari's Everyday Life, London: Routledge

Abdelmonem, M.G., 2011, Understanding everyday homes of urban communities: the Case of local streets (Hawari) of Old Cairo, Journal of Civil Engineering and Architecture,_Vol. 5, No. 11; pp.9961010.

Allan, G. and G. Crow, eds., 1989, Home and Family: Creating the Domestic Sphere, London, UK: Macmillan.

Alvira, R., 2010, El lugar al que se vuelve: Reflexiones sobre la familia, Pamplona, Spain: Eunsa.

Arendt, H., 1958, The Human Condition, Chicago: The University of Chicago Press.

Argandoña, A., 2004, Economic Ethics and Institutional Change, Journal of Business Ethics, 53(1-2), 191-201.

Argandoña, A., 2008, Integrating Ethics into Action Theory and Organizational Theory, Journal of Business Ethics, 78(3), 435-446.

Argandoña, A., 2018, The Home: Multidisciplinary Reflections, in A. Argandoña, ed., The Home: Multidisciplinary Reflections. Cheltenham, UK: Edward Elgar, 1-31.

Argandoña, A., 2019, Work at the Home: Purpose, Function, and Care, chapter 10 in this volume.

Bahr, H.M. and K.S. Bahr, 2001, Families and Self-Sacrifice: Alternative Models and Meanings for Family Theory, Social Forces, 79(4), 1231-1258.

Baier, A., 1987, Hume: The Woman's Moral Theorist? in E.F. Kittay and D. Meyers, eds., Women and Moral Theory. Lanham, MD: Rowman \& Littlefield.

Brizi, M.R., 2019, "Responsible Citizenship and our Common Home: Taking Care of the Natural Environment in Households and Beyond", chapter 5 in this volume.

Bower, S. N. (1980) Territory in urban settings. In Altman, l., et al. (eds.) Environment and culture; Human Behaviour and environment, Volume 4. New York: Plenum Press. Pp.179-193

Bubeck, D. , 1995, Care, Gender and Justice. Oxford, UK: Clarendon Press.

d'Entremont, A., 2018, Spatial Relationality and Domesticity: Reality and Functions of the Home from a Human Geography Perspective, in A. Argandoña, ed., The Home: Multidisciplinary Reflections. Cheltenham, UK: Edward Elgar, 163-175. 
Fox O'Mahony, L., 2013, The Meaning of Home: From Theory to Practice, International Journal of Law and Built Environment, 5 (2), 156-71.

Frezza, G., H. Keefe and M. Bertolaso, 2017, Work of the Home and Social Relationships as a Guide to Domestic Care for the Elderly, in F. Cavallo, V. Marletta, A. Monteriù and P. Siciliano, eds., Ambient Assisted Living. New York, NY: Springer.

Gilligan, C., 1982, In A Different Voice. Cambridge, Mass.: Harvard University Press.

González, A.M. and C. Iffland, eds. 2014, Care Professions and Globalization: Theoretical and Practical Perspectives. New York, NY: Palgrave Macmillan.

Graham, L.T., S.D. Gosling and C.K. Travis, 2015, The Psychology of Home Environments: A Call for Research on Residential Space, Perspectives on Psychological Science, 10(3), 346-56.

Grant, A., 2013. Give and Take: A Revolutionary Approach to Success. Why Helping Others Drives Our Success. London, UK: Weidenfeld \& Nicolson.

Halwani, R., 2003, Virtuous Liaisons: Care, Love, Sex, and Virtue Ethics. Peru, IL: Open Court.

Hamington, M., 2004, Embodied Care: Jane Addams, Maurice Merleau-Ponty and Feminist Ethics. Chicago, IL: University of Illinois Press.

Harris, S. (1997) Everyday Architecture. In Berke, D. \& Harris, S. Architecture of the everyday. Princeton: Princeton University Press.

Hayek, F.A., 1967, Studies in Philosophy, Politics and Economics. Chicago, IL: University of Chicago Press.

Held, V., 1993, Feminist Morality: Transforming Culture, Society, and Politics. Chicago, IL: University of Chicago Press.

Held, V., 2006, The Ethics of Care. New York, NY: Oxford University Press.

Karjalainen, P.T., 1993, House, Home and the Place of Dwelling, Scandinavian Housing and Planning Research, 10, 65-74.

Kemeny, J. (1992) Housing and social theory. London: Routledge.

Maclntyre, A., 1999, Dependent Rational Animals. Chicago: Carus Publishing Company.

Marcos, A., 2016, Vulnerability as a Part of Human Nature, in A. Masferrer and E. García, eds, Human Dignity of the Vulnerable in the Age of Rights: Interdisciplinary Perspectives. Dordrecht, the Netherlands: Springer, 29- 44.

Marcos, A. and M. Bertolaso, 2018, What is a Home? On the Intrinsic Nature of a Home, in A. Argandoña, ed., The Home: Multidisciplinary Reflections. Cheltenham, UK: Edward Elgar, 35-56.

Mayeroff, M., 1971. On Caring. New York, NY: Harper \& Row.

McLaren, M., 2001, Feminist Ethics: Care as a Virtue, in P. Desaultes and J Waugh, eds., Feminists Doing Ethics (Feminists Constructions), Lanham, MD: Rowman and Littlefield, 111-127.

Noddings, N., 1984, Caring: A Feminine Approach to Ethics and Moral Education. Berkeley, CA: University of California Press.

Patrão Neves, M., 2018, Self and Others: Home as a Cradle of a Non-Violent Relationship, in A. Argandoña, ed., The Home: Multidisciplinary Reflections. Cheltenham, UK: Edward Elgar, 57-76.

Pérez López, J.A., 1993, Fundamentos de dirección de empresas. Madrid, Spain: Rialp.

Ruddick, S., 1989, Maternal Thinking: Toward a Politics of Peace. New York, NY: Ballentine Books.

Ruddick, S., 1998, Care as Labor and Relationship, in M.S. Haflon and J.C. Haber, eds., Norms and Values: Essays on the Work of Virginia Held. Lanham, MD: Rowman \& Littlefield.

Tronto, J, 1994, Moral Boundaries: A Political Argument for an Ethic of Care. New York, NY: Routledge.

Witzel, M. and M. Warner, 2015, Taylorism Revisited: Culture, Management Theory and ParadigmShift, Journal of General Management, 40(3), 55-70. 
Zamagni, S., 2018, The Family and Economic Theorizing, A. Argandoña, ed., The Home: Multidisciplinary Reflections. Cheltenham, UK: Edward Elgar, 123-143.

Zárate, B., R. Agulles and C. León, 2019, From Care in the Home to the Transformation of Oher Care Environments in Homes, chapter 2 in this volume.

${ }^{1}$ Concerning the home's spatial or physical dimension, Karjalainen (1993), Fox O'Mahony (2013), Graham et al. (2015), Abdelmonem, (2011 \& 2016). These authors underscore that this dimension is not just physical but also psychological and spiritual (Argandoña 2018).

2 Ibid.

${ }^{3}$ Mallett, 'Understanding Home'

${ }^{4}$ Oxford English Dictionary. Online edition, as it appears on 25th June 2013.

${ }^{5}$ On the other hand, dwellings are used to denote the primitive, non-professional and mainly vernacular production of housing, while residence, shelter, and family are associated with the functions which humans require within their living space.

${ }^{6}$ The reader may perhaps think that this way of explaining the home is too traditionalist or even idealistic. This does not mean that we are not aware of the difficulties that arise in the home, or the criticisms that have been levelled at the different models. However, our purpose here is simply to explain this book's content and its three sections, care, people and work.

${ }^{7}$ The use of the word 'institution' here does not have an academic intention; it is understood simply as a way of organizing coexistence in certain specific circumstances, created not by human design but by society's selforganization (Hayek 1967). Argandoña (2004).

${ }^{8}$ The literature on care is usually focused from the perspective of the care professions; González and Iffland (2014).

${ }^{9}$ In this Introduction, we will not discuss issues such as transferring the responsibility for care from the family and the immediate environment to external professionals (who often become integrated as members of the needy person's home), or the reasons why care is mostly a woman's job, or why many care activities are poorly paid, etc.

${ }^{10}$ For some of these conceptions, see Held (2006), Ruddick (1998), Tronto (1994).

${ }^{11}$ It is true that a baby or an old person with dementia cannot be considered as having obligations toward the person who cares for them, at least not at that particular time. However, they can 'pay' for this care in other ways: when a hungry baby cries, it is a call to the carer to give the best of herself, and the baby's smile after it has been fed can be the best payment.

12 This is one of the reasons why the neoclassical economics of the family cannot be considered a complete theory of the home; Zamagni (2018).

${ }^{13}$ We say 'solely' by selfish motives because although they may be present, they cannot be the dominant motives: the father who cares for a sick child may do so hoping that in the future the child will look after him, but this extrinsic motivation cannot be the sole motivation: there must be, above all, an intrinsic or transcendent (Pérez López 1993) or prosocial motivation (Grant 2013).

${ }^{14}$ Held (1993) puts this more directly: viewed from political and social ethics, he sees the application of the ethics of care as the opportunity to create a culture that conceives as "its most important task the flourishing of children and the creation of human relationships".

${ }^{15}$ Obviously, the identity of the person or persons who are the centre of attention in the home changes as time goes by; the important point is that the actions performed within the home always target people, even when 
they apparently target an object: leaking roofs are repaired because the house, which is a means, must always be in the best possible state of repair for its people, who are the end.

${ }^{16}$ On the relationships between the home and society, Argandoña (2018, 15-17).

${ }^{17}$ For a development of these ideas, see Argandoña (chap. 10). 